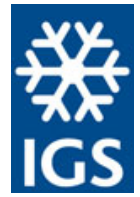

\section{Paper}

Cite this article: Rand C, Goehring BM (2019). The distribution and magnitude of subglacial erosion on millennial timescales at Engabreen, Norway. Annals of Glaciology 60(80), 73-81. https://doi.org/10.1017/aog.2019.42

Received: 12 June 2019

Revised: 13 November 2019

Accepted: 18 November 2019

First published online: 13 December 2019

\section{Key words:}

Beryllium-10; carbon-14; cosmogenic nuclides; Engabreen; glacial erosion

\section{Author for correspondence:}

Cari Rand, E-mail: crand1@tulane.edu (c) The Author(s) 2019. This is an Open Access article, distributed under the terms of the Creative Commons Attribution licence (http:// creativecommons.org/licenses/by/4.0/), which permits unrestricted re-use, distribution, and reproduction in any medium, provided the original work is properly cited.

\title{
The distribution and magnitude of subglacial erosion on millennial timescales at Engabreen, Norway
}

\section{Cari Rand and Brent M. Goehring}

Department of Earth and Environmental Sciences, Tulane University, 6823 St Charles Ave, New Orleans, LA 70118, USA

\section{Abstract}

We quantify the magnitude of millennial-scale glacial erosion at Engabreen, a temperate glacier in coastal northern Norway, using the in situ cosmogenic nuclides carbon-14 $\left({ }^{14} \mathrm{C}\right)$ and beryllium$10\left({ }^{10} \mathrm{Be}\right)$ in bedrock exposed recently by glacial retreat. Nuclide concentrations show no dependence on distance down or across the valley. As such, resulting Holocene erosion depths along two transects perpendicular to glacier flow are highly variable with no systematic distribution, ranging from 0.10 to $2.95 \mathrm{~m}$. We observed ${ }^{14} \mathrm{C}-{ }^{10} \mathrm{Be}$ ratios elevated above the production ratio in samples of abraded bedrock, which is counter to the expectation for surfaces covered during the Holocene and exposed only recently. Muon reactions produce nuclides at greater depths than do spallation reactions and ${ }^{14} \mathrm{C}$ at production rates at higher than those of ${ }^{10} \mathrm{Be}$, resulting in ${ }^{14} \mathrm{C}-{ }^{10} \mathrm{Be}$ ratios that increase with depth. Therefore, elevated ${ }^{14} \mathrm{C}-{ }^{10} \mathrm{Be}$ ratios indicate that sampled sites were deeply plucked during recent cover, the Little Ice Age in this case, and then rapidly abraded prior to retreat. Our results suggest that, while glacial erosion can generate a u-shaped valley profile over long periods of time (e.g., $10^{5}-10^{7}$ years), the discontinuous nature of glacial plucking produces spatially variable patterns of erosion over shorter millennial timescales.

\section{Introduction}

Determining rates of subglacial erosion is difficult due to the challenges involved in accessing the beds of glaciers and often requires relying upon proxy data rather than direct measurement (Hallet and others, 1996). Boreholes and slab experiments (e.g. Lappegard and Kohler, 2005; Iverson and others, 2007) allow for the direct measurement of erosion rates but only provide data over short-timescales (on the order of years) and must be repeated at numerous locations under a glacier to reveal spatial patterns of erosion. Techniques that examine glacial sediment volumes allow one to estimate erosion over much longer timescales (on the order of thousands of years or more) but are heavily dependent on subglacial and proglacial hydrology (e.g., Riihimaki and others, 2005) and cannot capture high-resolution spatial variations in erosion rates. Given the variable magnitude and possibly discontinuous nature of glacial erosion (Hooyer and others, 2012), care must be taken in scaling erosion rates to the time and spatial scales of interest for landscape evolution (e.g., Koppes and Montgomery, 2009). Better constraints on the magnitude of subglacial erosion on timescales longer than those of a single erosive event, but shorter than those of a full glacial cycle will aid in modeling the history of glacial and post-glacial landscapes (e.g., Harbor, 1992; Herman and others, 2011). Understanding the spatial distribution of erosion underneath glaciers better would improve interpretations of the landscapes created by glacial erosion.

We measured in situ cosmogenic carbon- $14\left({ }^{14} \mathrm{C}\right)$ and beryllium-10 $\left({ }^{10} \mathrm{Be}\right)$ concentrations in samples of glacially eroded bedrock exposed in the forefield of Engabreen, Norway (Fig. 1). The relationship between ${ }^{14} \mathrm{C}$ and ${ }^{10} \mathrm{Be}$ concentrations allows us to estimate the integrated duration of ice cover at our site during the Holocene and erosion depths over that duration. As we will show, nuclide concentrations indicate a very short $(\sim 1 \mathrm{ka})$ total burial duration with implications regarding the timing of erosion at the site. In particular, the in situ ${ }^{14} \mathrm{C}-{ }^{10} \mathrm{Be}$ ratio in our samples indicates that plucking and abrasion took place during the most recent period of ice cover, likely the Little Ice Age.

Cosmogenic-nuclide measurements can be made at multiple locations in a glacial forefield with relative ease, as samples can be collected from exposed bedrock. Our cosmogenic nuclide technique bridges the gap between the short- and long-term scales examined by other methods and improves spatial resolution and coverage by allowing us to target specific glacial features.

\section{Background}

Cosmogenic nuclides such as ${ }^{14} \mathrm{C}$ and ${ }^{10} \mathrm{Be}$ are products of the interaction of secondary cosmic ray particles (neutrons, protons and muons) with matter at or near the surface of the Earth. Cosmic rays are attenuated exponentially by the matter through which they pass. Furthermore, different production pathways have different attenuation lengths and therefore depth dependences (Gosse and Phillips, 2001). Neutrons emitted by the most productive pathway at the Earth's surface, spallation, are rapidly attenuated with depth and thus produce a 
Fig. 1. Maps displaying the location of our study site on regional to local scales. Orthophotographs and maps in parts A and B courtesy of (๑) Kartverket (a) Map showing the part of coastal Norway in which Engabreen is located. (b) Mosaiced orthophotos of the region surrounding our study site depicting Engabreen, Engabreevatnet and Holandsfjorden to the north. The approximate location of a farm overrun by a glacier advance about 1723 CE (Karlén, 1988) is also shown. The dominant foliation direction of the forefield bedrock is visible as color banding. (c) Satellite image of the Engabreen forefield, which contains our study site. Sample locations are marked with green circles and labeled with corresponding sample numbers. The red arrow indicates the direction of ice flow. Slope-perpendicular Nye channels appear above and to the right of the glacier in the image as dark, linear features. The main outlet channel draining Engabreen is visible as a light linear feature extending from the toe of the glacier to the upper left corner of the image.
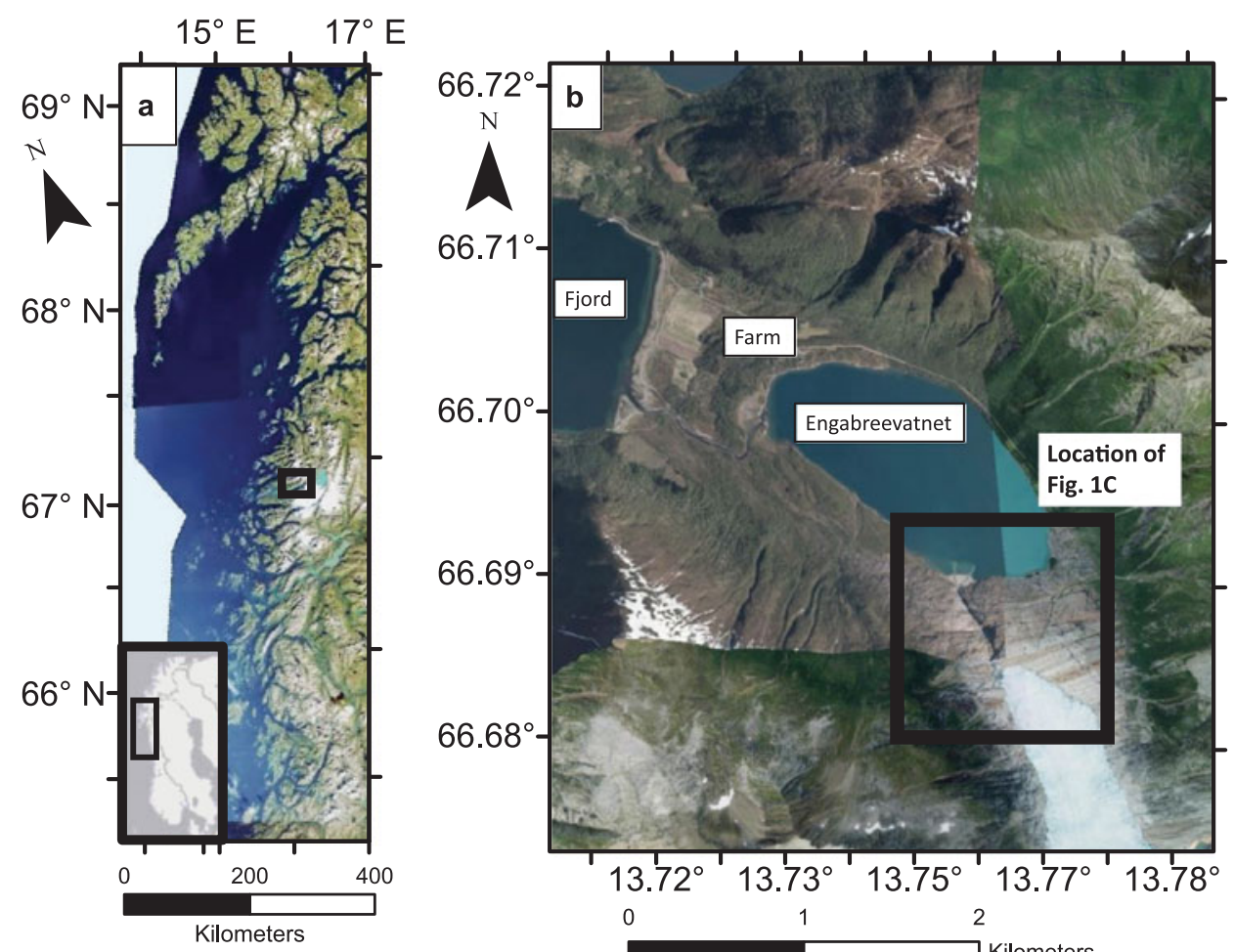

Kilometers

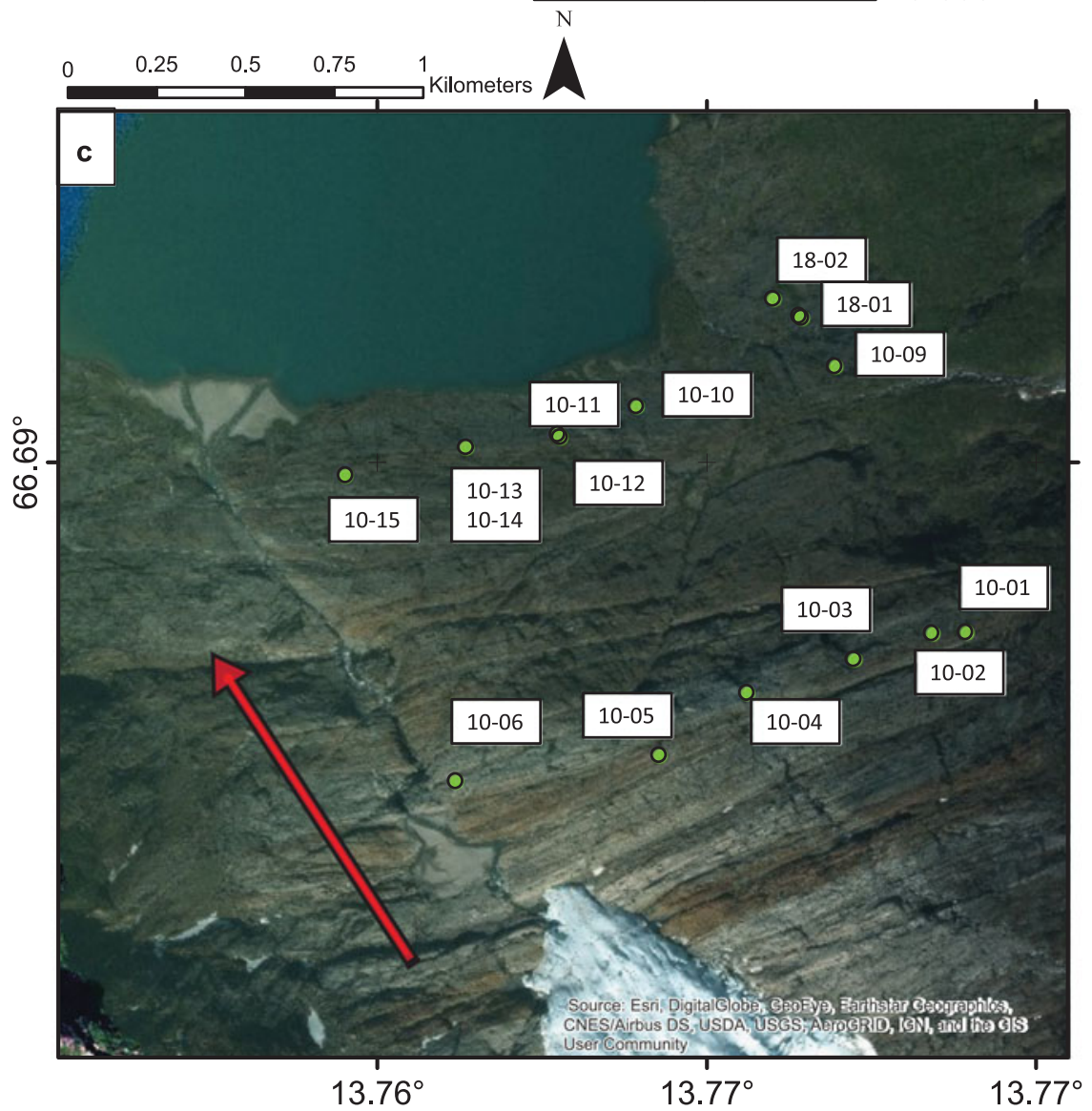

negligible number of nuclides below $\sim 5 \mathrm{~m}$ of bedrock. Other production pathways such as muon capture produce nuclides at the Earth's surface at a far lower rate than spallation does but are much less rapidly attenuated with depth. Production at depths from $\sim 5-100 \mathrm{~m}$ therefore is dominantly by muons (e.g., Gosse and Phillips, 2001; Balco, 2017).

The concentration of a cosmogenic radionuclide increases with the duration and degree of exposure until ultimately reaching secular equilibrium, the state in which production of nuclides is balanced by loss to radioactive decay and erosion. In its simplest case, the exposure age of a sample is therefore proportional to the concentration of a given nuclide (Lal, 1991). Short episodes of burial (e.g., by ice or sediment), however, may only partially deplete nuclide concentrations when production effectively ceases but decay continues, leaving a rock with 'inheritance' (i.e., nuclides produced during one or more previous episodes of 

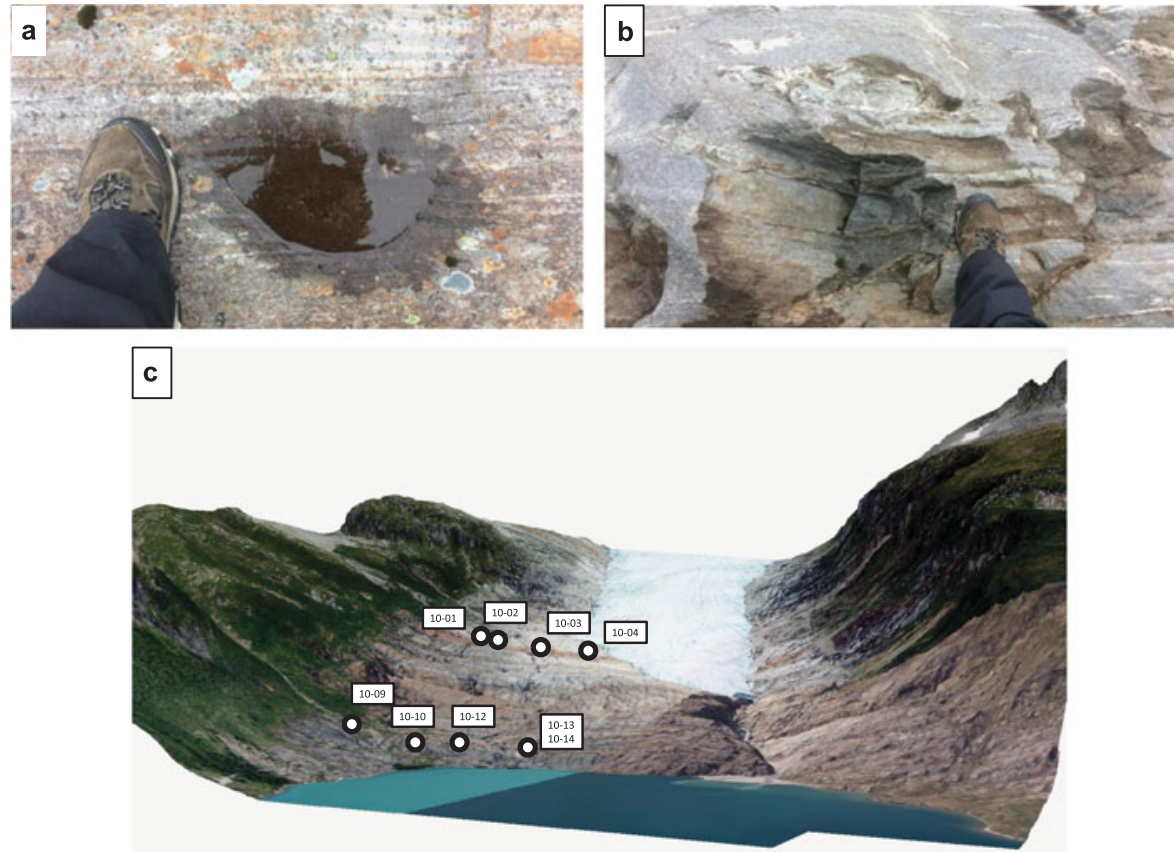

Fig. 2. (a) Example of a crescentic gouge filled with rainwater from site EG10-13 (on the lower transect). The curved face of the gouge bows downhill. Boot for scale. (b) Example of a plucked face near site EG10-06 (on the upper transect). Boot for scale. (c) Up-valley view of the Engabreen forefield consisting of orthophotographs draped over a digital terrain model. Sample sites from which data were used in this study are displayed as white circles labeled with sample names ('EG' has been excised from labels for clarity). The main Nye channel draining Engabreen can be seen at right. Note the stepped nature of the forefield, especially on the lower left of the image. Orthophotographs courtesy of $\odot$ Kartverket. exposure). Therefore, events in the history of a sample alter the concentrations and ratios of nuclides in a rock surface in characteristic ways. In a two-radionuclide system, halting nuclide production in a sample (e.g., burial) will modify nuclide ratios in favor of the longer-lived nuclide. Removing nuclides through erosion will also alter these ratios but in favor of the nuclide with a longer effective attenuation length. Analyzing multiple cosmogenic nuclides with different half-lives potentially allow one to identify and resolve the erosive and exposure histories of a sample.

Here we use ${ }^{10} \mathrm{Be}$ and ${ }^{14} \mathrm{C}$ to examine the exposure and erosion history of a glacial forefield. ${ }^{10} \mathrm{Be}$ is a frequently used nuclide for exposure dating with a $1.394 \mathrm{Ma}$ half-life, which sets its effective usable range on the order of centuries to millions of years (Chmeleff and others, 2010). ${ }^{10} \mathrm{Be}$ is commonly used on account of the relative ease of its isolation and measurement. ${ }^{14} \mathrm{C}$, with its much shorter 5.7 ka half-life (Olsson, 1968), is a useful nuclide to pair with ${ }^{10} \mathrm{Be}$ to identify burial episodes and erosion on Holocene timescales (Lal, 1991). The production rate of ${ }^{10} \mathrm{Be}$ is more strongly attenuated than the production rate of ${ }^{14} \mathrm{C}$ is, which aids in the estimation of the magnitude and timing of erosion. For example, the nuclide ratio in a sample at depth, exposed by a plucking event, will be rapidly overprinted by production at the surface rate. In an exposed sample a measured nuclide ratio indicative of production at depth implies that the plucking event which exposed it must have been recent.

\section{Setting}

Engabreen is an outlet glacier of the Svartisen ice cap in coastal northern Norway (Fig. 1). During the Pleistocene, the ice cap was overrun by and formed a part of the Scandinavian ice sheet (Olsen, 2002). Marine shells from terminal moraines at nearby Fonndalen date to $11990 \pm 60{ }^{14} \mathrm{C}$ years BP (Olsen, 2002; 13400 \pm 70 cal. yr BP, calibration curve MARINE13, http://calib.org), indicate that glaciers terminated near the current fjord shore at the beginning of the Younger Dryas. We assume that the glacier occupied a similar position following the Younger Dryas. The outermost moraine between the current terminus of Engabreen and Holandsfjorden is tentatively dated to about $1200 \mathrm{CE}$ (Worsley and Alexander, 1976) and historical records of ice advance (Karlén, 1988) show that the Engabreen terminus was several kilometers longer and terminated near sea level in historic times. The terminus has since retreated to $\sim 200 \mathrm{~m}$ a.s.l., exposing a bedrock forefield consisting dominantly of amphibolite and biotite garnet schists (Sigmond and others, 1984). The dominant bedrock foliation strikes perpendicular to sub-perpendicular to ice flow. In general, the bedrock surface is polished and striated, and many areas display crescentic gouges and plucking (Fig. 2). The forefield has a stepped habit descending as a series of rounded ridges or benches separated by numerous channels ranging from a few centimeters to several meters deep, interpreted as Nye channels by Messerli (2015).

We make several assumptions about Engabreen: that glacial cover and erosion during the Last Glacial Maximum was sufficient to decrease cosmogenic ${ }^{10} \mathrm{Be}$ and ${ }^{14} \mathrm{C}$ concentrations in the bedrock of our study site below detection limits and that any subaerial erosion or rock uplift was negligible over the timescales in question. Additionally, we assume that snow cover at our sites is transient (Theakstone, 2013) as the maritime climate at Engabreen causes temperatures to regularly rise above freezing, even during the winter months and the ground is commonly free of snow by mid-spring (Andreassen and others, 2006).

\section{Methods}

We sampled along two transects in $2010 \mathrm{CE}-$ one $\sim 200 \mathrm{~m}$ from the Engabreen terminus at $\sim 150 \mathrm{~m}$ a.s.l. and the other $\sim 500 \mathrm{~m}$ from the terminus at $\sim 20-30 \mathrm{~m}$ a.s.l. All sites were exposed within the two years prior to sampling. Samples were collected from exposed surfaces with a hammer and chisel. Topographic shielding was measured at each sample site by measuring the azimuth and inclination of horizon obstructions in a full circle around each sample. Topographic shielding corrections as well as sample location and size data are presented in Table 1.

Our sample transects generally span the forefield from the right-lateral valley wall to near the middle of the valley. We assume that samples from a given transect have the same exposure history (e.g., the in-transect differences are minimal on a millennial timescale) because the transects extend perpendicular to ice flow. Our sampling strategy, which targeted sites atop bedrock ridges and rises, lends us confidence that no substantial postglacial erosion of the sample surfaces was carried out by streams, 
Table 1. Sample locations and parameters

\begin{tabular}{llcccc}
\hline Sample & Transect & Latitude $\left({ }^{\circ} \mathrm{N}\right)$ & Longitude $\left({ }^{\circ} \mathrm{E}\right)$ & Elevation $(\mathrm{m}$ a.s.l.) & Thickness $(\mathrm{cm})$ \\
\hline EG10-01 & Upper & 66.68997 & 13.77321 & 181 & 2.25 \\
EG10-02 & Upper & 66.68996 & 13.77235 & 168 & 1.43 \\
EG10-03 & Upper & 66.68966 & 13.77007 & 155 & 1.79 \\
EG10-04 & Upper & 66.68918 & 13.76658 & 146 & 2.00 \\
EG10-09 & Lower & 66.69263 & 13.76990 & 27 & 0.9554 \\
EG10-10 & Lower & 66.69223 & 13.76488 & 20 & 0.9700 \\
EG10-12 & Lower & 66.69195 & 13.76289 & 24 & 3.21 \\
EG10-13 & Lower & 66.69182 & 13.76057 & 32 & 0.9667 \\
EG10-14 & Lower & 66.69182 & 13.76057 & 32 & 0.9474 \\
\hline
\end{tabular}

which preferentially flow through depressed channels along foliation planes and through former Nye channels (Messerli, 2015). This strategy additionally minimizes the effect of transient till cover at our sites, as loose sediment on local topographic highs would be preferentially transported to lows by gravity.

Samples were crushed, quartz fractions isolated and divided into aliquots for ${ }^{10} \mathrm{Be}$ and ${ }^{14} \mathrm{C}$ analysis. Aliquots for ${ }^{10} \mathrm{Be}$ analysis were dissolved in concentrated $\mathrm{HF}$ and $\mathrm{HNO}_{3}, \sim 0.25 \mathrm{mg}{ }^{9} \mathrm{Be}$ added, and $\mathrm{Be}$ isolated from other ions by ion exchange chromatography at the Tulane University Cosmogenic Nuclide Laboratory (TUCNL). ${ }^{10} \mathrm{Be}-{ }^{9} \mathrm{Be}$ ratios were determined via accelerator mass spectrometry (AMS) at the Purdue Rare Isotope Measurement Lab (PRIME). ${ }^{14} \mathrm{C}$ extraction was carried out at TUCNL following methods outlined in Goehring and others (2019). Briefly, the sample is fused in $\mathrm{LiBO}_{2}$ for one hour at $500^{\circ} \mathrm{C}$ to remove potential surface contaminants and then held for 3 hours at $1100^{\circ} \mathrm{C}$; released $\mathrm{C}$-species are oxidized to form $\mathrm{CO}_{2}$, which is then purified and graphitized via $\mathrm{H}_{2}$ reduction in the presence of Fe. ${ }^{14} \mathrm{C}-{ }^{13} \mathrm{C}$ ratios were measured at the National Ocean Science Accelerator Mass Spectrometry (NOSAMS) facility. Stable C isotope ratios were measured at the University of California, Davis Stable Isotope Facility. Data reduction followed Hippe and Lifton (2014).

We scaled sea level, high latitude production rates from the calibration dataset of Stroeven and others (2015) to our sample sites using the scaling scheme of Stone (2000) and muon scaling follows that in Balco (2017). Due to the high latitude, low elevation location of our samples, this scaling scheme is appropriate. Alternate scaling schemes, such as that of Lifton and others (2014), alter our scale factor by less than $1 \%$.

\section{${ }^{14} \mathrm{C}-{ }^{10} \mathrm{Be}$ isochrons}

Here, we follow the logic detailed in Goehring and others (2013) to determine the exposure duration and erosion depth of our samples. We modeled the attenuation of ${ }^{10} \mathrm{Be}$ production with depth via the following equation:

$$
P_{10}(z)=P_{10}(0) \varphi(z)
$$

in which $P_{10}(z)$ is the ${ }^{10} \mathrm{Be}$ production rate at depth $z(z=0$ denotes the surface) and $\varphi$ a term denoting the depth dependence of ${ }^{10} \mathrm{Be}$ production. $\varphi(z)$ typically takes the form of a negative exponential as production decreases with increasing mass depth. As discussed above, ${ }^{14} \mathrm{C}$ production differs in terms of depth dependence with respect to ${ }^{10} \mathrm{Be}$ and is furthermore dependent on the cosmic ray spectrum at a site. We account for this by introducing the parameter $\beta$ which relates the depth dependence of ${ }^{14} \mathrm{C}$ to ${ }^{10} \mathrm{Be}$, and we can therefore define the production rate of ${ }^{14} \mathrm{C}$ at depth by

$$
P_{14}(z)=P_{14}(0) \times(\beta \varphi(z)+1-\beta)
$$

in which $P_{14}(z)$ is the ${ }^{14} \mathrm{C}$ production rate at depth $z$ and $P_{14}(0)$ is the ${ }^{14} \mathrm{C}$ surface production rate. Where $\beta=1$, the ${ }^{14} \mathrm{C}$ and ${ }^{10} \mathrm{Be}$ production rates are equally attenuated by depth. Where $\beta<1$, the ${ }^{14} \mathrm{C}$ production rate is less attenuated than that of ${ }^{10} \mathrm{Be}$. Because ${ }^{14} \mathrm{C}$ production by muons exceeds ${ }^{10} \mathrm{Be}$ production by muons and because of the high-latitude and low-elevation location of our study site, we expect low values of $\beta$ (Heisinger and others, 2002a, 2002b).

Measured nuclide concentrations in a given sample $i$ are described by the following two equations:

$$
\begin{gathered}
N_{10 i}=P_{10 i} \varphi\left(z_{i}\right) t_{e} \\
N_{14 i}=\frac{P_{14 i}}{\lambda_{14}}[\beta \varphi(z)+(1-\beta)]\left(1-e^{-t_{e} \lambda_{14}}\right) e^{-\left(T_{0}-t_{e}\right) \lambda_{14}}
\end{gathered}
$$

in which $N_{10 i}$ and $N_{14 i}$ (both atoms $\mathrm{g}^{-1}$ ) and $P_{10 i}$ and $P_{14 i}$ (both atoms $\mathrm{g}^{-1} \mathrm{a}^{-1}$ ) are the ${ }^{10} \mathrm{Be}$ and ${ }^{14} \mathrm{C}$ concentrations and scaled production rates at the surface in sample $i$, respectively, and $T_{0}$ the initial exposure age. $\lambda_{14}$ is the decay constant of ${ }^{14} \mathrm{C}$ and $t_{e}$ the exposure duration of the sample. Note that the decay of ${ }^{10} \mathrm{Be}$ is neglected here, as it would be of negligible magnitude on a millennial timescale.

Solving for $\varphi(z)$ in Eqn (3) allows us to substitute this value into Eqn (4) to generate the equation for an isochron (Fig. 3):

$$
\frac{N_{14 i}}{P_{14 i}}=\frac{1}{\lambda_{14}}\left[\beta\left(\frac{N_{10 i}}{P_{10 i} t_{e}}\right)+(1-\beta)\right]\left(1-e^{-t_{e} \lambda_{14}}\right) e^{-\left(T_{0}-t_{e}\right) \lambda_{14}}
$$

which shows the ${ }^{14} \mathrm{C}$ concentration (normalized to its production rate) as a function of ${ }^{10} \mathrm{Be}$ concentration.

In the isochron shown in Figure 3, samples will plot progressively further from the origin as nuclides accumulate during exposure, while eroding samples will lose accumulated nuclides. Samples with little to no exposure and/or which are heavily eroded will therefore plot near the origin. Due to the different half-lives of the two nuclides in question, samples buried for the same length of time will all plot along a line drawn through the origin of the graph. This line is an isochron (colored lines in Fig. 3). The slope of the line fit to unburied samples will equal the ratio of the production rates of the measured nuclide. For a buried sample, increasing burial duration decreases the isochron slope such that the line is 'rotated towards' the axis on which the longer-lived nuclide is plotted (for an idealized example, see Fig. S1). Note that, unless a sample is buried very deeply, it will continue to accumulate nuclides (albeit at a very low rate). Dating approaches using multiple nuclides, such as the one we use here (developed in Goehring and others (2013)) allow us to graphically interpret the data from our sample transects. Samples from one transect should all have the same exposure and burial history within measurement precision. We employ a Bayesian fitting method to calculate the probability density 


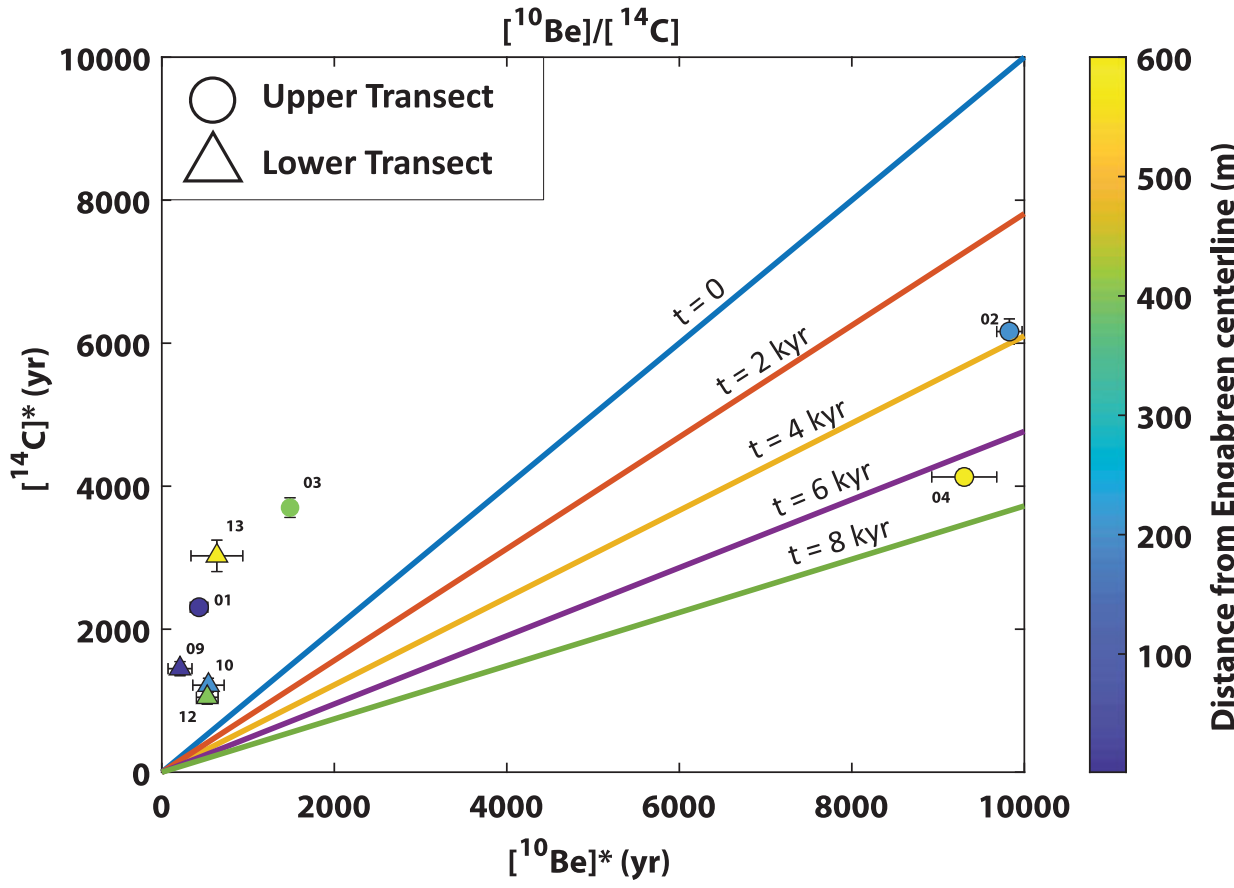

Fig. 3. Isochron diagram demonstrating the behavior of a two-radionuclide (beryllium-10 $\left[{ }^{10} \mathrm{Be}\right]$ and carbon-14 $\left.\left[{ }^{14} \mathrm{C}\right]\right)$ system. Nuclide concentrations are normalized by dividing the production rate of that nuclide, thus the unit of these values is years. Isochrons are labeled with the burial durations they represent. It is important to note that isochrons are calculated using surface production rates and are thus approximations. Substantial erosion will expose samples that accumulated nuclides at different rates, which is why samples can plot above the $t=0$ isochron. The upper transect samples with high ${ }^{10} \mathrm{Be}$ concentrations (EG10-02 and -04) are consistent with a minimum of 2-8 ka of cover while the lower-transect samples and the upper-transect samples with low concentrations plot above the $t=0$ isochron, indicating enhanced ${ }^{14} \mathrm{C}$ production relative to ${ }^{10} \mathrm{Be}$. Note, however, that we do not account for glacial erosion.

Table 2. Cosmogenic nuclide concentrations and apparent exposure ages

\begin{tabular}{|c|c|c|c|c|c|c|c|c|c|}
\hline Sample & Transect & $\left[{ }^{14} \mathrm{C}\right]^{\mathrm{a}}$ (atoms g $\left.\mathrm{g}^{-1}\right)$ & $\pm 1 \sigma\left(\right.$ atoms $\left.g^{-1}\right)$ & ${ }^{14} \mathrm{C}$ age (ka) & $\pm 1 \sigma(\mathrm{ka})$ & {$\left[{ }^{10} \mathrm{Be}\right]^{\mathrm{b}}$ (atoms g ${ }^{-1}$ ) } & $\pm 1 \sigma\left(\right.$ atoms $\left.g^{-1}\right)$ & ${ }^{10} \mathrm{Be}$ age (ka) & $\pm 1 \sigma(\mathrm{ka})$ \\
\hline EG10-01 & Upper & $4.16 \times 10^{4}$ & $1.54 \times 10^{3}$ & 2.7 & 0.2 & $2.10 \times 10^{3}$ & $4.96 \times 10^{2}$ & 0.4 & 0.2 \\
\hline EG10-02 & Upper & $11.1 \times 10^{4}$ & $3.19 \times 10^{3}$ & 11.3 & 1.5 & $45.4 \times 10^{3}$ & $6.81 \times 10^{2}$ & 9.1 & 0.9 \\
\hline EG10-03 & Upper & $6.56 \times 10^{4}$ & $2.44 \times 10^{3}$ & 4.9 & 0.5 & $7.11 \times 10^{3}$ & $3.06 \times 10^{2}$ & 1.4 & 0.2 \\
\hline EG10-04 & Upper & $7.11 \times 10^{4}$ & $1.86 \times 10^{3}$ & 5.5 & 0.5 & $44.2 \times 10^{3}$ & $17.9 \times 10^{2}$ & 9.0 & 1.2 \\
\hline EG10-09 & Lower & $2.26 \times 10^{4}$ & $1.54 \times 10^{3}$ & 1.5 & 0.2 & $0.876 \times 10^{3}$ & $5.75 \times 10^{2}$ & 0.2 & 0.3 \\
\hline EG10-10 & Lower & $1.87 \times 10^{4}$ & $1.48 \times 10^{3}$ & 1.2 & 0.2 & $2.20 \times 10^{3}$ & $7.39 \times 10^{2}$ & 0.5 & 0.3 \\
\hline EG10-12 & Lower & $1.63 \times 10^{4}$ & $1.49 \times 10^{3}$ & 1.1 & 0.2 & $2.18 \times 10^{3}$ & $5.20 \times 10^{2}$ & 0.5 & 0.2 \\
\hline EG10-13 & Lower & $4.80 \times 10^{4}$ & $3.49 \times 10^{3}$ & 3.7 & 0.7 & $2.70 \times 10^{3}$ & $12.6 \times 10^{2}$ & 0.6 & 0.6 \\
\hline EG10-14 & Lower & - & - & - & - & $0.936 \times 10^{3}$ & $4.30 \times 10^{2}$ & 0.2 & 0.2 \\
\hline
\end{tabular}

Apparent exposure ages are calculated via the CRONUS-Earth online exposure age calculator (version 3) using production rates scaled to sea level high latitude using the scaling scheme of Stone (2000) and corrected for topographic shielding. Note that samples EG10-13 and -14 were collected from different surfaces of the same site; EG10-13 from a horizontal surface and -14 from a lee-side vertical surface.

${ }^{\mathrm{a} C a r b o n}-14$ concentration.

${ }^{\mathrm{b}}$ Beryllium-10 concentration.

function for the exposure duration $\left(t_{e}\right)$ and $\beta$ value of our site following Goehring and others (2013). This method bypasses the normal approach of fitting the isochron slope and then solving for parameter values and instead directly determines parameter values while considering a range of geologic plausibilities encapsulated in the prior probabilities for known and unknown parameters.

\section{Erosion calculations}

We numerically determine the depth to which each sample has been glacially eroded using our measured ${ }^{10} \mathrm{Be}$ concentrations and the resulting exposure duration. The magnitude of erosion is calculated by defining $\varphi(z)$ in Eqn (3) as,

$$
\varphi(z)=P_{\mathrm{sp}} e^{-\frac{z \rho}{\Lambda_{\mathrm{sp}}}}+P_{\mu_{-}} e^{-\frac{z \rho}{\Lambda_{\mu_{-}}}}+P_{\mu_{f}} e^{-\frac{z \rho}{\Lambda_{\mu_{f}}}}
$$

in which ${ }_{\mathrm{sp}}$ indicates spallation and ${ }_{\mu-}$ and ${ }_{\mu f}$ indicate negative and fast muons, respectively (i.e. $P_{10 \text { sp }}$ would refer to the production rate of ${ }^{10} \mathrm{Be}$ via spallation, $\Lambda_{\mu_{f}}$ the attenuation length of production by fast muons, etc.). Note that the $P$ terms in Eqn (6) are normalized to the total surface production rate such that $\varphi(z)$ is a dimensionless parameter. We solve for $z$ numerically for each sample assuming $\Lambda_{\mathrm{sp}}=160 \mathrm{~g} \mathrm{~cm}^{-2}, \Lambda_{\mu_{-}}=1510 \mathrm{~g} \mathrm{~cm}^{-2}$ and $\Lambda_{\mu_{f}}$ $=4320 \mathrm{~g} \mathrm{~cm}^{-2}$ (Gosse and Phillips, 2001; Heisinger and others, $2002 a, 2002 b)$ for this calculation. One-sigma uncertainties on erosion depths are determined via 500-point Monte Carlo bootstrapping.

\section{Results}

\section{Cosmogenic nuclide concentrations}

All samples yield ${ }^{10} \mathrm{Be}$ and ${ }^{14} \mathrm{C}$ concentrations above detection limits, indicating that the samples were exposed for sufficient time to generate an inventory and not eroded deeply enough to remove the entire inventory. The concentrations of either nuclide do not vary in a systematic way with distance along a transect perpendicular to the flow of Engabreen, but concentrations in lower transect samples are generally lower compared to concentrations in the upper transect samples (Table 2).

${ }^{10} \mathrm{Be}$ concentrations vary across the upper transect by an order of magnitude, from $2100 \pm 500$ atoms $\mathrm{g}^{-1}$ to $45000 \pm 680$ atoms $\mathrm{g}^{-1}$ (Table 2). The samples with the highest concentrations (EG10-02 and EG10-04) are adjacent to the samples with the 


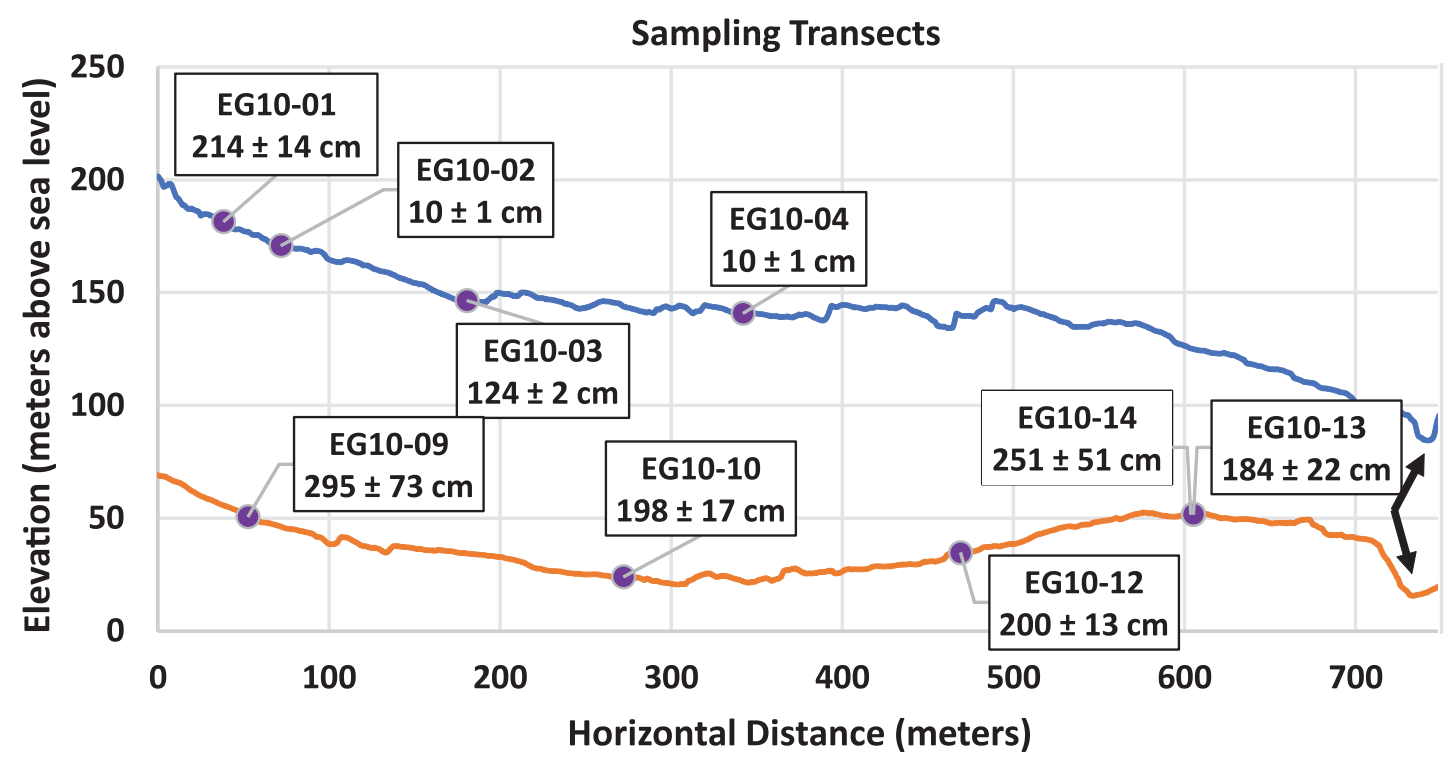

Fig. 4. Elevation profiles of our two sampling transects looking up-glacier. Sample sites (purple circles) are shown projected onto the upper (blue line) and lower (orange line) transects. Samples are labeled with their sample name and erosion depth. The main Nye channel carrying meltwater out from below Engabreen along the left-lateral wall of the valley is denoted with a black arrow. Elevation data from the Norwegian Mapping Authority.

Table 3. Calculated erosion depths and ${ }^{14} \mathrm{C}-{ }^{10} \mathrm{Be}$ concentration ratios

\begin{tabular}{llcc}
\hline Sample & Transect & Erosion depth $(\mathrm{m})$ & ${ }^{14} \mathrm{C}-{ }^{10} \mathrm{Be}$ \\
\hline EG10-01 & Upper & $2.14 \pm 0.14$ & $19.8 \pm 4.74$ \\
EG10-02 & Upper & $0.10 \pm 0.01$ & $2.4 \pm 0.08$ \\
EG10-03 & Upper & $1.24 \pm 0.02$ & $9.2 \pm 0.52$ \\
EG10-04 & Upper & $0.10 \pm 0.01$ & $1.6 \pm 0.08$ \\
EG10-09 & Lower & $2.95 \pm 0.73$ & $25.8 \pm 17.03$ \\
EG10-10 & Lower & $1.98 \pm 0.17$ & $8.5 \pm 2.93$ \\
EG10-12 & Lower & $2.00 \pm 0.13$ & $17.5 \pm 1.91$ \\
EG10-13 & Lower & $1.84 \pm 0.22$ & - \\
EG10-14 & Lower & $2.51 \pm 0.51$ & \\
\hline
\end{tabular}

Erosion depths calculated using the integrated exposure duration determined using the Bayesian isochron method. Carbon-14 concentration was not measured from sample EG10-14, so its ratio is omitted from this table.

lowest concentrations (EG10-01 and EG10-03). Upper-transect ${ }^{14} \mathrm{C}$ concentrations range from $42000 \pm 1500$ atoms g ${ }^{-1}$ to 110 $000 \pm 3200$ atoms g $\mathrm{g}^{-1}$.

${ }^{10} \mathrm{Be}$ concentrations for the lower transect are between $880 \pm$ 580 atoms $\mathrm{g}^{-1}$ and $2700 \pm 1300$ atoms g ${ }^{-1}$ (Table 2). Lower transect ${ }^{14} \mathrm{C}$ concentrations range from $16000 \pm 1500 \mathrm{~g}^{-1}$ to 48000 \pm 3500 atoms $\mathrm{g}^{-1}$. The proportional decrease in concentrations from the upper transect to the lower is less for ${ }^{14} \mathrm{C}$ than it is for ${ }^{10} \mathrm{Be}$. Samples EG10-13 and EG10-14 are from the same location - EG10-14 was collected from a vertical lee face and EG10-13 from the stoss side of the same feature. ${ }^{14} \mathrm{C}$ concentrations were not measured from sample EG10-14 because the sample only contained enough quartz for ${ }^{10} \mathrm{Be}$ analysis.

\section{Exposure history}

The resulting exposure duration for Engabreen, inclusive of both transects, is $11.0 \pm 0.2 \mathrm{ka}$. Given the close spatial proximity of our two transects, we calculated the exposure duration via the method of Goehring and others (2013) using all of our samples instead of calculating separate exposure durations for each transect. Recent and historical rates of retreat (Rekstad, 1893) indicate that Engabreen is capable of retreating the $\sim 300 \mathrm{~m}$ between our two transects within the $200 \mathrm{yr}$ of the $1 \sigma$ uncertainty on our calculated exposure duration. Subtracting the exposure duration of the transects from the initial exposure age of $12.0 \mathrm{kcal}$ yr BP assumed from Olsen (2002) yields a burial duration of $1.0 \pm 0.2 \mathrm{ka}$. We base our $T_{0}$ assumption on the idea that shells buried under moraines near the current fjord shore closely limit the maximum initial exposure of our sample site $\sim 2 \mathrm{~km}$ inland.

\section{Erosion depths}

Erosion depths vary by more than an order of magnitude along the upper transect $(10 \pm 1 \mathrm{~cm}, \mathrm{EG} 10-02$ and -04 , to $214 \pm$ $14 \mathrm{~cm}$, EG10-01) and to a lesser degree along the lower transect $(184 \pm 22 \mathrm{~cm}$, EG10-13, to $295 \pm 73 \mathrm{~cm}$, EG10-09; Fig. 4, Table 3). Additionally, sites with very different erosion depths are located adjacent to one another (e.g., EG10-01 and -02).

The resulting uncertainties on erosion depths are a product of two factors (Fig. S2). The first is that the larger relative uncertainties are associated with low nuclide concentrations as a result of nonlinear effects as the total number of in situ nuclides (not concentrations) approaches the number of atoms in the process blanks. The second is that, as depth increases, any given nuclide concentration profile becomes flatter and the resulting erosion depth uncertainty larger. Thus, any given measurement precision will be compatible with a wider range of erosion depths relative to shallower parts of the concentration profile and thus the resulting uncertainty will be larger.

\section{Discussion}

The spatial distribution of glacial abrasion rates is typically characterized as being dependent on sliding velocity and modification by valley-wall drag (Hallet, 1979) and the effective normal stress exerted by tools (such as plucked rock fragments embedded in basal ice) on the bed of a glacier (Hallet, 1981). As such, abrasion rates are expected to vary approximately quadratically across valley. This ideal model of abrasion does not, at first glance, adequately describe our results. Were abrasion the dominant control on nuclide concentrations at our site, nuclide concentrations would decrease quadratically toward the centerline of the glacier where sliding velocities are greatest (Fig. 5). The lack of any such clear trend indicates that additional processes acted on the Engabreen forefield to produce the spatial pattern of nuclide 

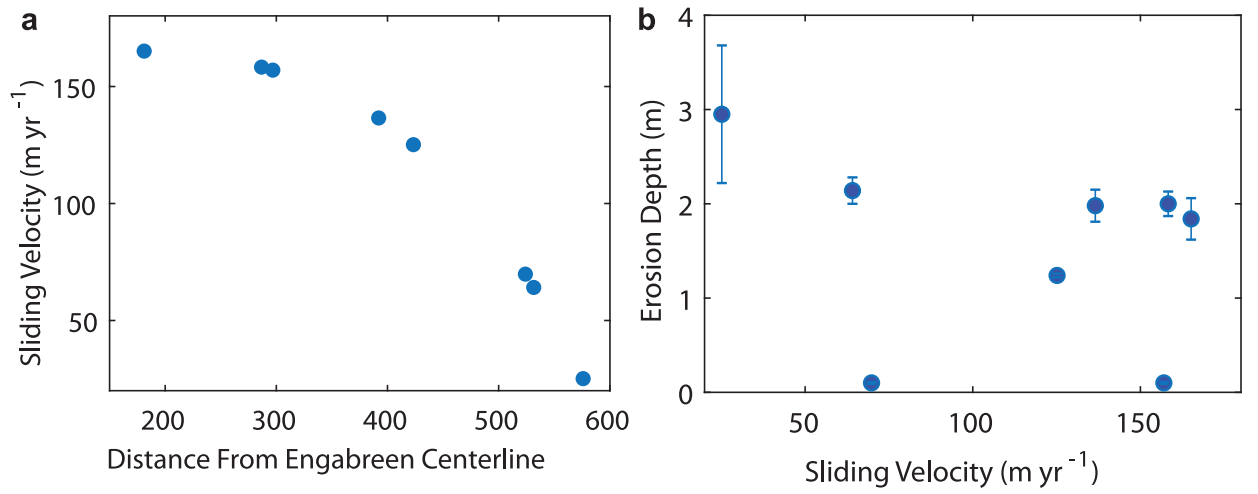

Fig. 5. Sliding velocity and erosion depth calculated at our sample sites. (a) Sliding velocity as predicted by the method of Nye (1952), which takes drag from valley walls and floor into account when calculating basal sliding velocity. We calculated these velocities given the surface velocities reported for the Engabreen terminus in Jackson and others (2005). The plot here shows the expected quadratic dropoff in velocity due to drag from the valley walls. (b) Calculated erosion depths vs calculated sliding velocity.

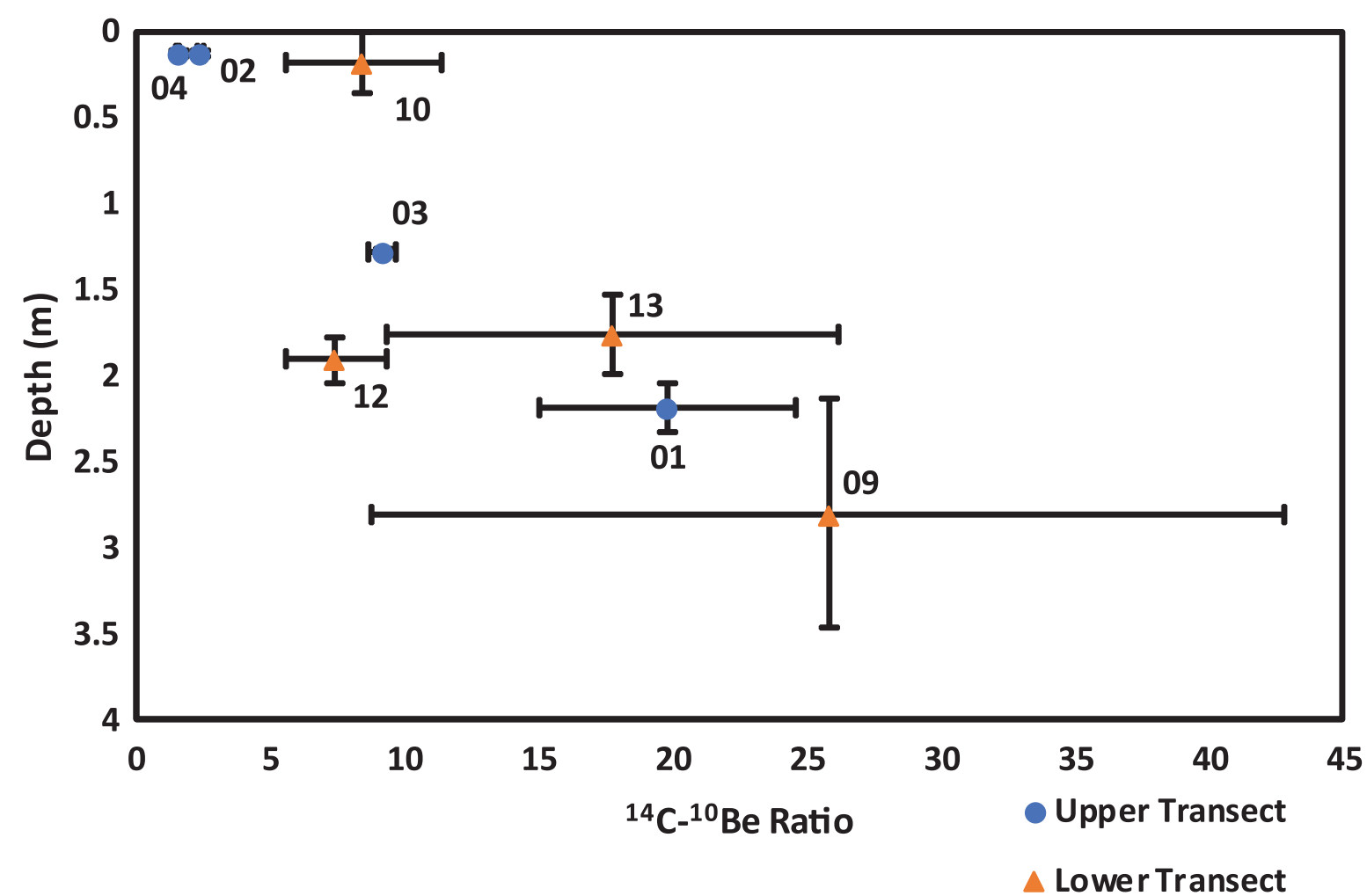

Fig. 6. ${ }^{14} \mathrm{C}-{ }^{10} \mathrm{Be}$ ratios of samples from the upper (blue circles) and lower (orange triangles) transects. The shallowly eroded samples of the upper transect (EG10-02 and EG10-04) have the lowest ratios and these ratios decrease with the calculated erosion depth, demonstrating the reduced attenuation of in situ ${ }^{14} \mathrm{C}$ production with depth relative to that of ${ }^{10} \mathrm{Be}$. 'EG10-' has been excised from data labels for clarity.

concentrations we observe. Given the lack of valley-scale trend and the areal geomorphology, this indicates that localized plucking has occurred.

Furthermore, we observe a wide-range of ${ }^{14} \mathrm{C}_{-}{ }^{10} \mathrm{Be}$ concentration ratios (Table 3 ), including samples with ratios exceeding the ${ }^{14} \mathrm{C}-{ }^{10} \mathrm{Be}$ production rate ratio $(\sim 3.76)$. These samples are particularly interesting because we know these sites were buried during the Little Ice Age and exposed very recently. They would thus be expected to have ${ }^{14} \mathrm{C}-{ }^{10} \mathrm{Be}$ ratios less than the production ratio. It is possible that measurement or sample preparation could account for the elevated ${ }^{14} \mathrm{C}-{ }^{10} \mathrm{Be}$ ratios, particularly given the low overall concentrations and correspondingly large uncertainties. This is especially true for the lower transect ${ }^{10} \mathrm{Be}$ concentrations, as the total number of ${ }^{10} \mathrm{Be}$ atoms in the process blank is a significant fraction of the measured number of ${ }^{10} \mathrm{Be}$ atoms in a sample. However, we could not identify any systematic issues with either the ${ }^{10} \mathrm{Be}$ or ${ }^{14} \mathrm{C}$ measurements. Therefore, we discount measurement errors as a cause of the elevated ${ }^{14} \mathrm{C}-{ }^{10} \mathrm{Be}$ ratios. Rather, we propose that elevated production of ${ }^{14} \mathrm{C}$ at depth by muon capture relative to ${ }^{10} \mathrm{Be}$ and rapid deep erosion leads to the observed ratios. Because muons have longer attenuation lengths than fast neutrons do, the relative magnitude of the muon component of cosmogenic-nuclide production increases with depth while the absolute production rate decreases. Since ${ }^{14} \mathrm{C}$ has a significantly higher production rate by muons than does ${ }^{10} \mathrm{Be}$ (when normalized to surface production rates, the muogenic ${ }^{14} \mathrm{C}-{ }^{10} \mathrm{Be}$ production rate ratio equals $\sim 13.62$ at our sites), the ${ }^{14} \mathrm{C}-{ }^{10} \mathrm{Be}$ ratio increases with depth (Heisinger and others, $2002 a, 2002 b)$. As production by muons dominates production beyond depths of $\sim 2.5 \mathrm{~m}$ (Briner and others, 2016), samples from deeply eroded sites represent rock in which ${ }^{14} \mathrm{C}$ production was proportionally greater (compared to ${ }^{10} \mathrm{Be}$ production) than at lesser depths (Fig. 6). The short, $\sim 1$ ka burial duration of our site requires erosion rates in excess of $2 \mathrm{~mm} \mathrm{a}^{-1}$ to explain the highest 
${ }^{14} \mathrm{C}-{ }^{10} \mathrm{Be}$ ratios exhibited by our samples (Table 3 ). It is unlikely that abrasion alone would erode the bedrock beneath Engabreen that quickly, as reported subglacial-abrasion rates are commonly lower than this by roughly an order of magnitude (e.g., Briner and Swanson, 1998; Goehring and others, 2011). Further, it is unlikely that the required high abrasion rates operated while sparing adjacent sampled bedrock from significant erosion. Scaling the erosion rates calculated from recently plucked sites would therefore likely overestimate long-term erosion rates for a glacier.

Given sample surfaces that were originally at depth and the spatial heterogeneity of erosion, plucking must be invoked to explain the elevated ${ }^{14} \mathrm{C}-{ }^{10} \mathrm{Be}$ ratio. Furthermore, the plucking must have occurred during the Little Ice Age instead of during Last Glacial Maximum cover, as the ${ }^{14} \mathrm{C}-{ }^{10}$ Be ratio in our samples had not re-equilibrated to the surface production-rate ratio. Figure 6 demonstrates this observation; the two deeply eroded samples of the upper transect (EG10-01 and -03) and the more deeply eroded lower transect all have high ${ }^{14} \mathrm{C}_{-}{ }^{10} \mathrm{Be}$ ratios.

Plucking will remove evidence of past abrasion at a site. As all but one of our sites showed evidence of abrasion but some also showed evidence of plucking, the abrasion must have occurred between the plucking event and the exposure of the sample sites. Historical records and our data imply that the Engabreen forefield was uncovered for the majority of the Holocene and only buried recently. Therefore, the isotopic and geological data allow us to construct an ordered timeline of events at our plucked sites: plucking during Little Ice Age cover, abrasion during or before glacial retreat, followed by a period of exposure short enough that high ${ }^{14} \mathrm{C}-{ }^{10} \mathrm{Be}$ ratios are still preserved in exposed surfaces.

Supplementary material. The supplementary material for this article can be found at https://doi.org/10.1017/aog.2019.42.

Acknowledgements. We wish to acknowledge the Purdue Rare Isotope Measurement laboratory, the Woods Hole National Ocean Sciences Accelerator Mass Spectrometry facility and the University of California, Davis Stable Isotope Facility for sample nuclide measurements. We also thank Kristine Hippe and two anonymous reviewers for constructive reviews that improved this manuscript.

\section{References}

Andreassen LM and 5 others (2006) Modelling the climate sensitivity of Storbreen and Engabreen, Norway. Norwegian Water Resources and Energy Directorate (NVE) Report No. 3.

Balco G (2017) Production rate calculations for cosmic-ray-muon-produced $10 \mathrm{Be}$ and $26 \mathrm{Al}$ benchmarked against geological calibration data. Quaternary Geochronology 39, 150-173.

Briner JP, Goehring BM, Mangerud J and Svendsen JI (2016) The deep accumulation of $10 \mathrm{Be}$ at Utsira, southwestern Norway: implications for cosmogenic nuclide exposure dating in peripheral ice sheet landscapes. Geophysical Research Letters 43(17), 9121-9129.

Briner JP and Swanson TW (1998) Using inherited cosmogenic 36Cl to constrain glacial erosion rates of the Cordilleran ice sheet. Geology 26(1), 3-6.

Chmeleff J, von Blanckenburg F, Kossert K and Jakob D (2010) Determination of the 10Be half-life by multicollector ICP-MS and liquid scintillation counting. Nuclear Instruments and Methods in Physics Research Section B: Beam Interactions with Materials and Atoms 268(2), 192-199.

Goehring BM and others (2011) The Rhone Glacier was smaller than today for most of the Holocene. Geology 39(7), 679-682.

Goehring BM, Muzikar P and Lifton NA (2013) An in situ ${ }^{14} \mathrm{C}-{ }^{10} \mathrm{Be}$ Bayesian isochron approach for interpreting complex glacial histories. Quaternary Geochronology 15, 61-66.
Goehring BM, Wilson J and Nichols K (2019) A fully automated system for the extraction of in situ cosmogenic carbon-14 in the Tulane university cosmogenic nuclide laboratory. Nuclear Instruments and Methods in Physics Research Section B: Beam Interactions with Materials and Atoms 455, 284-292.

Gosse JC and Phillips FM (2001) Terrestrial in situ cosmogenic nuclides: theory and application. Quaternary Science Reviews 20(14), 1475-1560.

Hallet B (1979) A theoretical model of glacial abrasion. Journal of Glaciology 23(89), 39-50.

Hallet B (1981) Glacial abrasion and sliding: their dependence on the debris concentration in basal ice. Annals of Glaciology 2, 23-28.

Hallet B, Hunter L and Bogen J (1996) Rates of erosion and sediment evacuation by glaciers: a review of field data and their implications. Global and Planetary Change 12, 213-235.

Harbor JM (1992) Numerical modeling of the development of U-shaped valleys by glacial erosion. Geological Society of America Bulletin 104(10), 1364-1375.

Heisinger B and others (2002a) Production of selected cosmogenic radionuclides by muons: 1. Fast muons. Earth and Planetary Science Letters 200 (3-4), 345-355.

Heisinger B and others (2002b) Production of selected cosmogenic radionuclides by muons: 2. Capture of negative muons. Earth and Planetary Science Letters 200(3-4), 357-369.

Herman F, Beaud F, Champagnac JD, Lemieux JM and Sternai P (2011) Glacial hydrology and erosion patterns: a mechanism for carving glacial valleys. Earth and Planetary Science Letters 310(3-4), 498-508.

Hippe $\mathrm{K}$ and Lifton NA (2014) Calculating isotope ratios and nuclide concentrations for In situ cosmogenic $14 \mathrm{C}$ analyses. Radiocarbon 56(3), 11671174 .

Hooyer TS, Cohen D and Iverson NR (2012) Control of glacial quarrying by bedrock joints. Geomorphology 153, 91-101.

Iverson NR and others (2007) Soft-bed experiments beneath Engabreen, Norway: regelation infiltration, basal slip and bed deformation. Journal of Glaciology 53(182), 323-340.

Jackson M, Brown IA and Elvehøy H (2005) Velocity measurements on Engabreen, Norway. Annals of Glaciology 42, 29-34.

Karlén W (1988) Scandinavian glacial and climatic fluctuations during the Holocene. Quaternary Science Reviews 7(2), 199-209.

Koppes MN and Montgomery DR (2009) The relative efficacy of fluvial and glacial erosion over modern to orogenic timescales. Nature Geoscience 2(9), 644.

Lal D (1991) Cosmic ray labeling of erosion surfaces: in situ nuclide production rates and erosion models. Earth and Planetary Science Letters 104(2-4), 424-439.

Lappegard G and Kohler J (2005) Determination of basal hydraulic systems based on subglacial high-pressure pump experiments. Annals of Glaciology 40(1), 37-42.

Lifton N, Sato T and Dunai TJ (2014) Scaling in situ cosmogenic nuclide production rates using analytical approximations to atmospheric cosmic-ray fluxes. Earth and Planetary Science Letters 386, 149-160.

Messerli A (2015) Surface Velocities and Hydrology at Engabreen: Observations from Feature Tracking and Hydro-Meteorological Measurements (Diss). The Niels Bohr Institute, Faculty of Science, University of Copenhagen.

Nishiizumi K and 5 others (2007) Absolute calibration of 10Be AMS standards. Nuclear Instruments and Methods in Physics Research Section B: Beam Interactions with Materials and Atoms 258(2), 403-413.

NOSAMS (2018). Woods Hole Oceanographic Institution; [updated 2018 January 17]. Available at http://www.whoi.edu/nosams/general-statementof-14c-procedures (Accessed 19 November 2018).

Nye JF (1952) The mechanics of glacier flow. Journal of Glaciology 2(12), 82-93.

Olsen L (2002) Mid and Late Weichselian, ice-sheet fluctuations northwest of the Svartisen glacier, Nordland, Northern Norway. Geological Survey of Norway Bulletin 440, 39-52.

Olsson IU (1968) Modern aspects of radiocarbon datings. Earth-Science Reviews 4, 203-218.

Rekstad J (1893) Beretning om en undersøgelse af Svartisen, foretagen I somrene 1890 og 1891. Archiv for Mathematik og Naturvidenskab 16, 266-321.

Riihimaki CA, MacGregor KR, Anderson RS, Anderson SP and Loso MG (2005) Sediment evacuation and glacial erosion rates at a small alpine glacier. Journal of Geophysical Research: Earth Surface 110(F3). 
Sigmond EMO, Gustavson M and Roberts D (1984) Bedrock map of Norway, 1: 1 million. Norges Geologiske Undersøkelse, Trondheim.

Stone JO (2000) Air pressure and cosmogenic isotope production. Journal of Geophysical Research: Solid Earth 105(B10), 23753-23759.

Stroeven AP and others (2015) A new Scandinavian reference 10 Be production rate. Quaternary Geochronology 29, 104-115.
Theakstone WH (2013) Long-term variations of the seasonal snow cover in Nordland, Norway: the influence of the North Atlantic Oscillation. Annals of Glaciology 54(62), 25-34.

Worsley P and Alexander MJ (1976) Glacier and environmental changes neoglacial data from the outermost moraine ridges at Engabreen, northern Norway. Geografiska Annaler: Series A, Physical Geography 58(1-2), 55-69.

\section{Appendix - Geochemical data tables}

Table A1. Carbon-14 sample geochemical data

\begin{tabular}{|c|c|c|c|c|c|c|c|c|c|c|c|}
\hline Sample ID* & Quartz (g) & Yield ( $\mu \mathrm{g} C$ ) & Diluted mass $(\mu \mathrm{g} C)$ & $\delta^{13} \mathrm{C}(\% 0)$ & $\pm 1 \sigma(\% 0)$ & ${ }^{14} \mathrm{C} / \mathrm{C}$ & $\pm 1 \sigma$ & $F_{\mathrm{m}}$ & $\pm 1 \sigma$ & {$\left[{ }^{14} \mathrm{C}\right]^{\dagger}\left(\right.$ at $\left.\mathrm{g}^{-1}\right)$} & $\pm 1 \sigma\left(\right.$ at g $\left.{ }^{-1}\right)$ \\
\hline $\mathrm{EG} 10-01^{\mathrm{a}}$ & 4.9909 & 472.7 & 472.7 & - & - & $1.15 \times 10^{-14}$ & $2.55 \times 10^{-16}$ & 0.011 & 0.0002 & $4.16 \times 10^{4}$ & $1.54 \times 10^{3}$ \\
\hline $\mathrm{EG} 10-02^{\mathrm{b}}$ & 10.1817 & 39.9 & 426.5 & -44.11 & 0.50 & $6.64 \times 10^{-14}$ & $13.16 \times 10^{-16}$ & 0.056 & 0.0005 & $10.99 \times 10^{4}$ & $3.72 \times 10^{3}$ \\
\hline EG10-03 ${ }^{b}$ & 7.9905 & 51.7 & 438.9 & -44.02 & 0.50 & $3.71 \times 10^{-14}$ & $7.30 \times 10^{-16}$ & 0.031 & 0.0006 & $6.44 \times 10^{4}$ & $3.46 \times 10^{3}$ \\
\hline $\mathrm{EG} 10-04^{\mathrm{a}}$ & 4.5368 & 15.6 & 110.1 & -2.36 & 1.80 & $7.01 \times 10^{-14}$ & $5.87 \times 10^{-16}$ & 0.061 & 0.0005 & $7.11 \times 10^{4}$ & $1.86 \times 10^{3}$ \\
\hline EG10-09 ${ }^{a}$ & 4.6723 & 10.2 & 105.7 & -5.46 & 0.94 & $3.22 \times 10^{-14}$ & $3.45 \times 10^{-16}$ & 0.029 & 0.0003 & $2.26 \times 10^{4}$ & $1.54 \times 10^{3}$ \\
\hline $\mathrm{EG} 10-10^{\mathrm{a}}$ & 4.8203 & 6.4 & 107.5 & -5.36 & 0.50 & $2.88 \times 10^{-14}$ & $3.84 \times 10^{-16}$ & 0.027 & 0.0004 & $1.87 \times 10^{4}$ & $1.48 \times 10^{3}$ \\
\hline $\mathrm{EG} 10-12^{\mathrm{a}}$ & 4.7523 & 14.2 & 108.7 & -5.33 & 0.50 & $2.61 \times 10^{-14}$ & $3.64 \times 10^{-16}$ & 0.024 & 0.0003 & $1.63 \times 10^{4}$ & $1.49 \times 10^{3}$ \\
\hline $\mathrm{EG} 10-13^{\mathrm{a}}$ & 2.0525 & 9.7 & 111.0 & -14.02 & 0.50 & $2.93 \times 10^{-14}$ & $3.69 \times 10^{-16}$ & 0.027 & 0.0003 & $4.80 \times 10^{4}$ & $3.49 \times 10^{3}$ \\
\hline
\end{tabular}

Process blanks

\begin{tabular}{lc}
\hline Sample blank & Effective blank (atoms) \\
\hline a & $9.51 \times 10^{4}$ \\
b & $27.1 \times 10^{4}$
\end{tabular}

NOSAMS reports the ${ }^{14} \mathrm{C}-{ }^{13} \mathrm{C}$ ratios of samples relative to the Ox-II standards produced at TUCNL, which is calibrated to that of the National Bureau of Standards Oxalic Acid I (NIST SRM 4990) (NOSAMS, 2018).

*Sample ID superscripts correspond to Sample Blanks.

†Carbon-14 concentration.

Table A2. Beryllium-10 sample geochemical data

\begin{tabular}{|c|c|c|c|c|c|c|}
\hline Sample ID* & Quartz mass (g) & Be carrier (mg Be) & ${ }^{10} \mathrm{Be} /{ }^{9} \mathrm{Be}$ & $\pm 1 \sigma$ & {$\left[{ }^{10} \mathrm{Be}\right]^{\dagger}$ (atoms g ${ }^{-1}$ ) } & $\pm 1 \sigma\left(\right.$ atoms $\left.g^{-1}\right)$ \\
\hline $\mathrm{EG} 10-01^{\mathrm{a}}$ & 25.5337 & 0.2704 & $4.02 \times 10^{-15}$ & $6.24 \times 10^{-16}$ & $2.10 \times 10^{3}$ & $4.96 \times 10^{2}$ \\
\hline $\mathrm{EG} 10-02^{\mathrm{b}}$ & - & - & - & - & $45.4 \times 10^{3}$ & $6.81 \times 10^{2}$ \\
\hline $\mathrm{EG} 10-03^{\mathrm{b}}$ & - & - & - & - & $7.11 \times 10^{3}$ & $3.06 \times 10^{2}$ \\
\hline $\mathrm{EG} 10-04^{\mathrm{a}}$ & 33.9257 & 0.2709 & $83.8 \times 10^{-15}$ & $3.23 \times 10^{-16}$ & $44.2 \times 10^{3}$ & $17.9 \times 10^{2}$ \\
\hline EG10-09 ${ }^{a}$ & 25.0174 & 0.2695 & $2.28 \times 10^{-15}$ & $7.32 \times 10^{-16}$ & $0.876 \times 10^{3}$ & $5.75 \times 10^{2}$ \\
\hline $\mathrm{EG} 10-10^{\mathrm{a}}$ & 26.3137 & 0.2686 & $4.29 \times 10^{-15}$ & $10.3 \times 10^{-16}$ & $2.20 \times 10^{3}$ & $7.39 \times 10^{2}$ \\
\hline $\mathrm{EG} 10-12^{\mathrm{a}}$ & 25.0792 & 0.2687 & $4.11 \times 10^{-15}$ & $6.50 \times 10^{-16}$ & $2.18 \times 10^{3}$ & $5.20 \times 10^{2}$ \\
\hline $\mathrm{EG} 10-13^{\mathrm{a}}$ & 12.8050 & 0.2690 & $2.99 \times 10^{-15}$ & $8.41 \times 10^{-16}$ & $2.70 \times 10^{3}$ & $12.6 \times 10^{2}$ \\
\hline
\end{tabular}

Process blanks

\begin{tabular}{lcccc}
\hline Sample blank & Be carrier (mg Be) & ${ }^{10} \mathrm{Be} /{ }^{9} \mathrm{Be}$ & $\pm 1 \sigma$ & $\pm 1 \sigma($ atoms $)$ \\
\hline a & 0.26936 & $1.06 \times 10^{-15}$ & $3.20 \times 10^{-16}$ & $1.91 \times 10^{4}$ \\
b & - & - & - & $57.5 \times 10^{2}$ \\
\hline
\end{tabular}

The ${ }^{10} \mathrm{Be}-{ }^{9} \mathrm{Be}$ ratio reported by PRIME Lab utilizes the $07 \mathrm{KNSTD}$ standard, with a ${ }^{10} \mathrm{Be}-{ }^{9} \mathrm{Be}$ concentration ratio of $(2.79 \pm 0.03) \times 10^{-11}$ (Nishiizumi and others, 2007). Note that the 'Be Carrier' column has units of milligrams of beryllium added, not milligrams of carrier added. Sample and blank information other than concentrations and concentration errors for EG10-02 and -03 were not reported due to a missing laboratory notebook.

*Sample ID superscripts correspond to Sample Blanks.

†Beryllium-10 concentration. 